\title{
A BOTTOM-UP SUPPLY-SIDE SIMULATION MODEL OF RESIDENTIAL AND COMMUNITY ENERGY SYSTEMS USING SYSTEM DYNAMICS
}

\author{
Bilal Bugaje \\ Peter Rutherford \\ Faculty of Engineering \\ University of Nottingham, Nottingham, NG7 2RD \\ bilal.bugaje@nottingham.ac.uk \\ Faculty of Engineering \\ University of Nottingham, Nottingham, NG7 2RD \\ peter.rutherford@nottingham.ac.uk
}

\author{
Mike Clifford \\ Faculty of Engineering \\ University of Nottingham, Nottingham, NG7 2RD \\ mike.clifford@nottingham.ac.uk
}

\begin{abstract}
Increasing interest in distributed generation of energy, increasing number of participants in energy planning, and the interdisciplinary nature of energy planning, provide an opportunity for new tools to model energy systems from bottom-up. This paper presents bottom-up supply-side models of residential and community energy systems based on a case study using System Dynamics. The simulation models are constructed to facilitate Systems Thinking, which can enable interdisciplinary and transdisciplinary approaches, whilst performing analyses expected from similar models. The modelling process is presented followed by discussion on the outcome of the process. The paper concludes with future work on the model.
\end{abstract}

Keywords: System Dynamics, Energy System, Simulation, Systems Thinking

\section{INTRODUCTION}

Centralised electricity generation has been facing many challenges like constraints to efficiency and capacity, which can be resolved by Distributed Generation (DG) (Mendes et al 2011; Takahashi et al 2005). There is a trend in research and industry towards more distributed generation, especially from renewable sources (Sadeghi et al 2017). Global trends like liberalisation of energy markets, environmental protection and sustainable development have increased interest for energy planning at smaller geographic scales (Cormio et al 2003). Moreover, the main trends in energy planning include: growing interest in DG based on renewables; growing community awareness on environmental issues; increasing number of decision makers in energy planning (Mirakyan and De Guio, 2013). These trends may also explain the rise of the "prosumer" (Rathnayaka et al 2015), who is both producer and consumer of energy. Since the implementation of energy system depends on whether the user is a producer or consumer (Project SENSIBLE Partners, 2015), the prosumer presents a challenge to implementation of energy systems, and consequently energy planning. In distributed residential and community energy systems, any individual can be a planner.

Energy planning involves many areas of problem, activities and participants, which makes it unavoidably interdisciplinary, or even transdisciplinary. Modelling the operations of energy systems is essential in energy planning of different scales especially communities and cities (Huang et al 2015; Mirakyan and De Guio, 2013). Based on the review in (Huang et al 2015), it seems that at the heart of bottom-up energy planning is techno-economic assessments, techno-ecological assessments and whatif (scenario and sensitivity) analyses. Accordingly, it has been observed in (Manfren et al 2011) that there is a need for energy planning tools that can facilitate communication in an interdisciplinary or transdisciplinary manner whilst carrying out expected analyses. This would also benefit researchers taking an interdisciplinary or transdisciplinary approach. 
This study aims to demonstrate creation and possible uses of System Dynamics (SD) models for bottom-up supply-side simulation models of residential energy systems and community energy systems. Some of the contributions of this study include the use of discrete feedback in SD to model energy systems, as well as the use of a diagrammatic transdisciplinary method for simulation.

The next section provides a background to the study by looking at relevant aspects of System Dynamics, followed by a literature review of similar models in light of System Dynamics. Then there is a brief section on methods followed by a section on results and discussion, in which the modelling process, outcomes and validity considerations are presented. Finally, there is a concluding section.

\section{BACKGROUND}

\subsection{System Dynamics}

System Dynamics (SD) is a method of modelling and simulation of complex systems - with features such as feedback, nonlinearity, delay - that can analyse dynamic behaviour over time based on the principles of system structures (Forrester, 1961; Sterman, 2000). SD provides a common means of representation and communication across several disciplines and beyond formal disciplines which makes it an interdisciplinary, as well as a transdisciplinary, method. This is achieved by using the generic language of systems as outlined in the system principles (Forrester, 1997); making SD a systems approach. In addition, SD meets the four minimum criteria (system hierarchy; means of communication; adaptation; emergent properties) for Systems Thinking according to (Checkland, 2012; Checkland, 1981).

All System Dynamics models have at least one of two general aims which can be achieved via a variety of architecture (which includes but not limited to Ordinary Differential Equations, Agent Based Modelling, Discrete Event Simulation, or a combination) (Rahmandad and Sterman, 2018; Sterman, 2000): improve understanding of a system by explaining its dynamics; virtually simulate and analyse possible configurations of the system. Some models have both aims. Improving understanding is applicable to continuous feedback, whereas virtual simulation and analysis is applicable to both continuous and discrete feedback. SD also has other benefits that are characteristic of the method which all SD models can benefit from. These include being a: method of structural realism; quantitatively rigorous soft method; diagrammatic simulation method; method based on systems language. These properties make SD a suitable method for interdisciplinary and transdisciplinary approaches to research or projects.

In $\mathrm{SD}$, variables are mainly categorised into stocks or flows; others are auxiliary variables and constants. In stock and flow diagrams, links can be material links or information links represented as double arrows or single arrows respectively. The direction of material links indicate the movement of the same quantity between two variables, but information links simply indicate dependence. Stocks are accumulations, while flows are the rate of accumulation.

\subsection{Literature Review}

Energy models have been classified in (Van Beeck, 1999; Timmerman et al 2014; Hall and Buckley, 2016) along similar dimensions. However all their classifications are limited to software packages, excluding generic modelling methods like MATLAB and System Dynamics. This study is primarily about a modelling method, not specific problems of the modelled system, even though efficacy of the model will be demonstrated via examples of problems. The models of interest are bottom-up energy supply models of (the operation of) microgrids; which can be found in (Ravindra and Iyer, 2014; Hong et al 2017; Mukherjee et al 2017; Aguilar-Jiménez et al 2018; Kitson et al 2018; Dhundhara et al 2018; He et al 2018; Adefarati and Bansal, 2019; Nnaji et al 2019; Raji and Luta, 2019; Xu et al 2019; Astriani et al 2019; Bukar et al 2019; Castillo-Calzadilla et al 2019; Cornélusse et al 2019; Ge et al 2019; Griego et al 2019).

Given the varied purposes of the models listed, their capabilities will not be compared. It is sufficient that the tools or methods have been demonstrated to carry out what they aim to do in their respective studies. Therefore the use of SD in this study is not to improve on analytic capabilities where other methods fail, but to highlight its other beneficial features, in addition to its analytic 
capabilities. To the knowledge of the authors, there has been no bottom-up supply-side simulation of an energy system using System Dynamics.

The main limitation of SD in this study is the inability to implement programming concepts that may be required for metaheuristic algorithms without a third party integration. SD can be understood as a modelling method that can present a model with three layers of complexity: the diagram layer; the equations layer; the programming layer/add-on. In the case of Energy Planning, different participants may be interested in the different layers, respectively: the public and prosumers; management; industry partners. Researchers may be interested in any of the layers. It has been observed that bottom-up energy models are characterised by the first two thermodynamic laws, economic and environmental constraints (Huang et al 2015). The thermodynamic laws can be implemented in the SD model of this study as energy conservation and energy conversion loss, whilst the constraints can be simulated via impact assessments. In addition, SD can offer more realism via the principle of causal connectedness; which aims to ensure that causal links in the model must be justified by evidence from the real system.

\subsection{Project SENSIBLE}

The case study to be modelled is Project SENSIBLE (Storage Enabled Sustainable Energy for Buildings and Communities). The aim of SENSIBLE "is to understand the economic benefits that energy storage can bring to households, communities, and commercial buildings" (https://www.projectsensible.eu/ accessed 1 July 2018). SENSIBLE explores the use of energy storage at residential and community levels implemented in real communities. One of the communities is in The Meadows, Nottingham, UK. The plan was to implement a Community Energy System and several Residential Energy Systems made up of power electronic and communication devices; a smart grid. The project has been well documented and available at the website (https://www.projectsensible.eu/downloads/ accessed 1 July 2018).

\section{METHODS}

Equivalent processes of system dynamics have been outlined in Table 1 based on (Randers, 1980; Richardson and Pugh III, 1981; Roberts et al 1983; Sterman, 2000). In addition, the corresponding parallel validity tests have been outlined in (Sterman, 2000; Shreckengost, 1984; Qudrat-Ullah and Seong, 2010). The main method of sourcing data is via archival research, and the data sources include project deliverables, quantitative data from operational devices, and specification sheets of devices.

Table 1 Stages of System Dynamics process, tools, expected outcome and corresponding validity tests

\begin{tabular}{|c|c|c|c|c|}
\hline Order & Stage & Tool(s) & Expected Outcome & Validity Test \\
\hline 1 & $\begin{array}{l}\text { Problem } \\
\text { articulation }\end{array}$ & $\begin{array}{l}\text { Model } \\
\text { Boundary } \\
\text { Chart }\end{array}$ & $\begin{array}{l}\text { Problem theme; Problem statement; } \\
\text { Time scale and range; Key } \\
\text { variables and concepts. }\end{array}$ & Boundary Adequacy \\
\hline 2 & $\begin{array}{l}\text { Construction of } \\
\text { conceptual model }\end{array}$ & $\begin{array}{l}\text { Stock and } \\
\text { Flow } \\
\text { Diagram }\end{array}$ & A conceptual model & Structure Verification \\
\hline \multirow[t]{6}{*}{3} & \multirow{6}{*}{$\begin{array}{l}\text { Formulation of } \\
\text { simulation model }\end{array}$} & \multirow{6}{*}{$\begin{array}{l}\text { Stock and } \\
\text { Flow } \\
\text { Diagram }\end{array}$} & \multirow[t]{6}{*}{ A simulation model } & \\
\hline & & & & Dimensional Consistency \\
\hline & & & & Parameter Verification \\
\hline & & & & Extreme Conditions \\
\hline & & & & Behaviour Reproduction \\
\hline & & & & Sensitivity Analysis \\
\hline 4 & $\begin{array}{l}\text { Conclude Validity } \\
\text { Test }\end{array}$ & - & $\begin{array}{l}\text { Confidence, or means to establish } \\
\text { confidence, in the model's structure } \\
\text { and behaviour. }\end{array}$ & Not Applicable \\
\hline 5 & Analyses & - & $\begin{array}{l}\text { Answers to questions about the real } \\
\text { system via the simulation system }\end{array}$ & $\begin{array}{l}\text { Beyond the scope of this } \\
\text { research. }\end{array}$ \\
\hline
\end{tabular}




\section{RESULTS AND DISCUSSIONS}

The discussion that follows is based on the stages of the System Dynamics process and their corresponding validity tests. The validity tests will be addressed in form of responses to the questions they pose, as outlined in (Sterman, 2000). For brevity, each question will not be dedicated a subsection. Moreover, the discussion that follows is not limited to the questions of the validity tests.

\subsection{Problem Articulation}

The purpose of the System Dynamics exercise is to create simulation models of residential and community energy systems from Project SENSIBLE to demonstrate scenario analysis, technoeconomic impact analysis, and techno-ecological impact analysis. Therefore the focus is on the operational, economic and environmental dimensions of the system. The time resolution of the simulation model is minutes because the field devices measure in minutes, and the time range is the duration of a day in order to make system behaviour visually distinguishable in a time-series graph.

Table 2 is the model boundary chart showing variables from the real system that will be modelled (endogenous and exogenous) and those that will not be modelled (excluded). Forecasting, storage optimisation and energy market services are modules within SENSIBLE that rely on proprietary algorithms (which include machine learning and genetic algorithms) and stored data. The outcome of these modules are signals to the energy systems which have been represented as exogenous variables.

Table 2 Model Boundary Chart

\begin{tabular}{|l|l|c|}
\hline \multicolumn{1}{|c|}{ Endogenous } & \multicolumn{1}{|c|}{ Exogenous } & Excluded \\
\hline - Consumption & - Load demand & - Reactive \\
- Battery State of Charge & - PV production & power \\
(SoC) & - Storage efficiency & Battery \\
- PV Consumption & - Conversion efficiency & lifetime \\
- PV Loss & - Signal to charge battery from grid & Auto \\
- Power Import & - Signal to supply load from grid without battery & discharge \\
- Power Export & discharge & \\
- PV Charging & - Signal to sell to grid without battery charge & \\
- PV Charging Loss & - Signal to limit maximum battery SoC from grid & \\
- PV Discharging & - Power ratings & \\
- PV Discharging Loss & & \\
\hline
\end{tabular}

\subsection{Conceptual Model}

Data about structure of the system was obtained from project documents: SENSIBLE Deliverables (https://www.projectsensible.eu/downloads/ accessed 1 July 2018). The residential and community energy systems are made of devices with a variety of capabilities. Each system could be modelled as an electricity system or information system, depending on the level of abstraction; as an electric circuit or information network. The systems as information system is better suited for the purpose of this study. The chosen level of aggregation is to model power in Watts and energy in Watt-minutes because most of the monitoring devices measure power in Watts.

A conceptual model of a Residential Energy System is shown in Figure 1, created using Vensim. The conceptual model can facilitate Systems Thinking because it is a diagram that explicates the interdependence in a system with feedback (Richmond, 1993; Forrester, 1994; Sterman, 2000). In addition to causal dependency indicated by all arrows, other observable features of the material links (double arrows) are energy conservation and energy conversion loss. The simulation model is built on the conceptual model. 


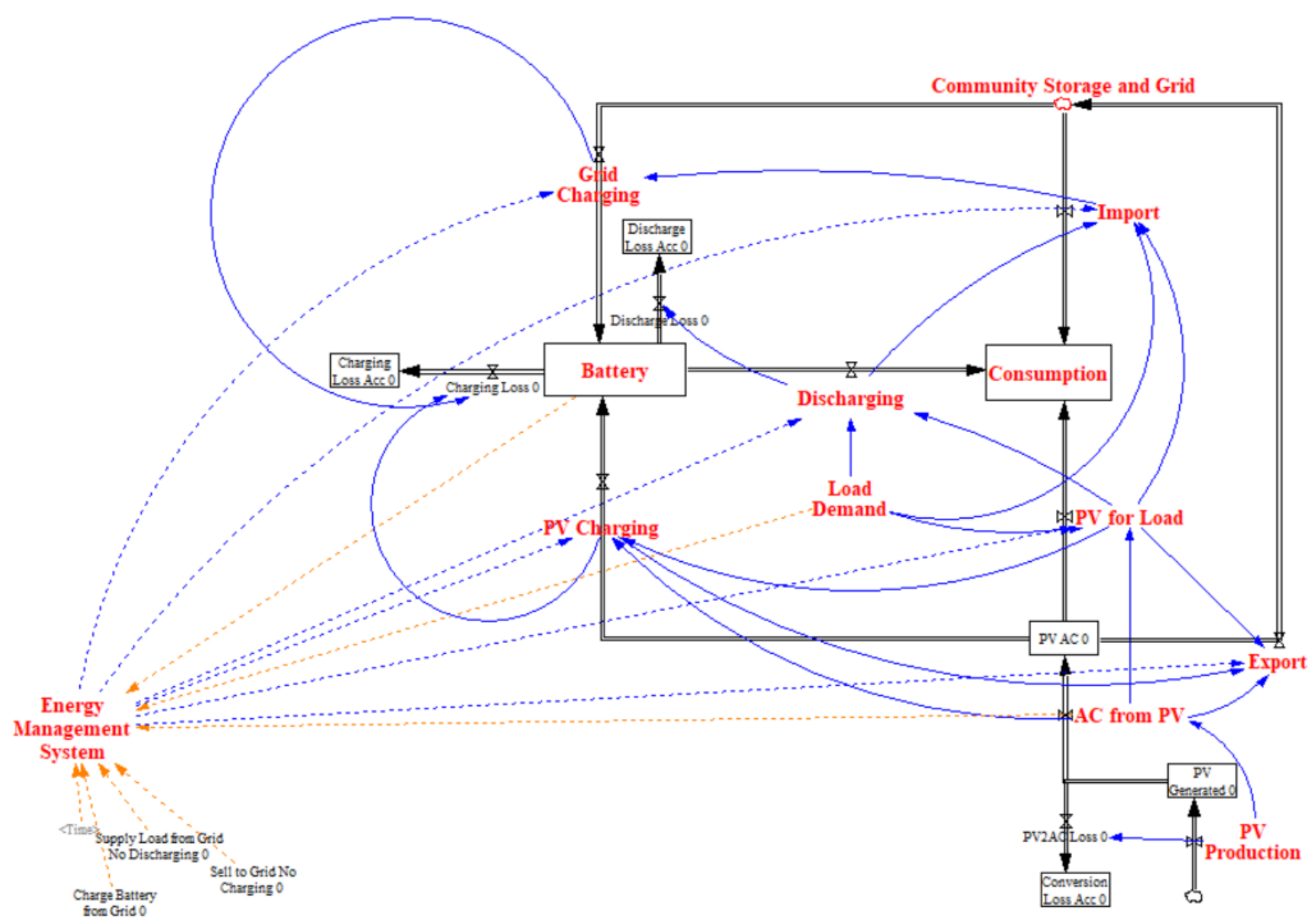

Figure 1 Conceptual Model of a Residential Energy System showing causal dependencies among system elements using Stock and Flow Diagram. Dotted arrows indicate connections to and from the Energy Management System.

\subsection{Simulation Model}

For moments where load demand exceeds the combined rated values of all power sources, the unserved load is monitored separately as a validation measure. The simulation models implement the following in fidelity with the real system:

- Nonlinear efficiency and loss of energy during energy conversion by the power inverters.

- Energy conservation such that energy can be accounted for from source to load and loss.

- Enforcement of causal connectedness such that decision making elements make decisions using only information realistically available to them.

All system rules have been derived from description of three use cases applicable to the Nottingham Demonstrator of SENSIBLE (https://www.projectsensible.eu/downloads/ accessed 1 July 2018). The discrete feedback of the system is determined by the system decisions. The model was checked using the integrated Units Checking tool in Vensim and there are no errors, which confirms dimensional consistency. All parameter values are obtained from the same project documents used for conceptual model, as well as device specification documents. Extreme values are handled within equations, for example, using rated values of devices. Only one normaliser variable in the model has no real world counterpart but it is used in order to balance the units. It is called "Energy to Power Normaliser", which has a value of 1 and a unit of 1/time. This is used in equations of the following variables where a power value is to be determined from energy values: Charge Power to Max; Discharge Power to Min; and Grid Charge Limit.

To run a simulation, a time series of electric load is provided as input. Data from real residences with four different composition of devices were obtained. 


\subsubsection{Validity Test - Behaviour Reproduction}

The aim is to investigate if a model reproduces historical behaviour in the system. See Figure 2a for example. In general, for the same 24 hour period, the behaviour of the simulation models of the four residences matches data from the real system; for the variables of battery charging, battery discharging, power import, power export, and battery state of charge. The exception is in the case of import and export for the residence with Grid + Battery + PV, but more significant in the export. The discrepancy in export follows behaviour that does not match what has been documented.

Additionally, the error may be explained by one of three reasons: the real data is erroneous; or the documents did not capture properly the system's rules; or the rules were not properly applied in the simulation. The error is likely to be from the real data because other simulations resulted in reasonable match, including variables of the same residence (charging, discharging and battery state of charge), and the rules are from the same sources. Also, the use of optimisation signals (to export power or not), does not explain the error. At the moment, efforts are being made to obtain real data from other residences with the same configuration in order to verify.

\subsection{Analyses}

\subsubsection{Scenario Analysis}

The aim is to simulate and compare the dynamic behaviour of different compositions of the system. See Figure $2 b$ for examples; it visually compares power import from simulations of Community Energy Systems with and without a community battery. During daylight hours, there is significant import from the grid in the scenario where there is no community battery because there is no stored energy that may have been obtained at night when energy is cheaper.

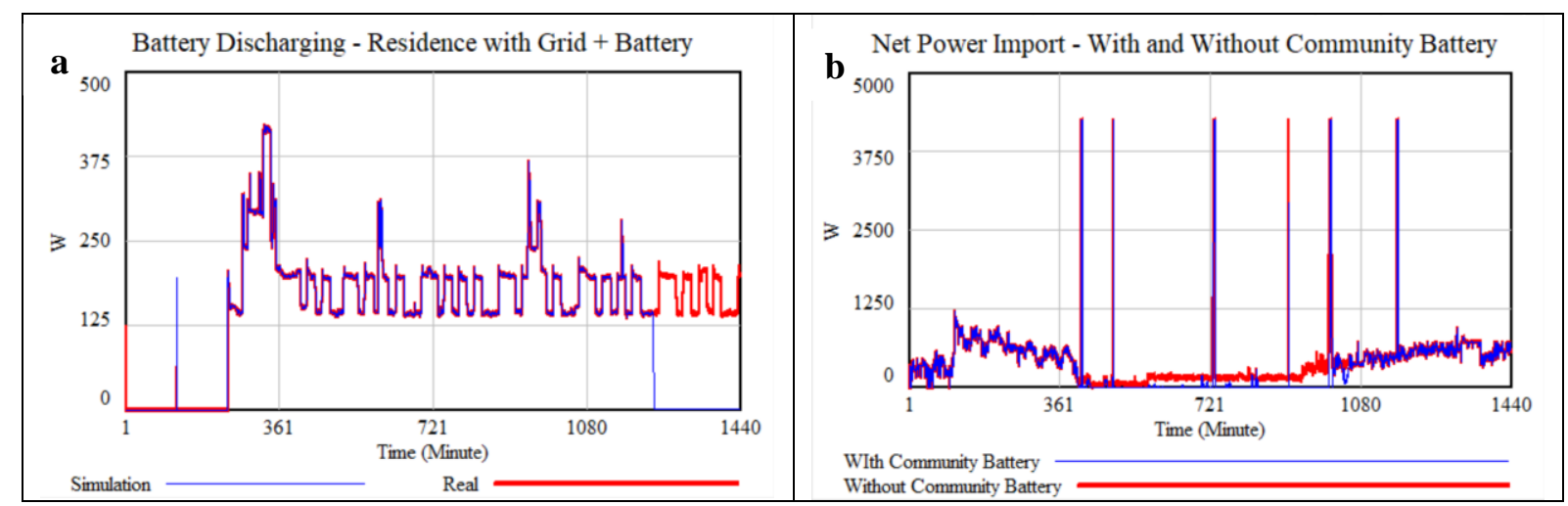

Figure 2 a) Example of behaviour comparison between SD simulation and the real system for different residences. b) Example of Scenario Analysis comparing the same Community Energy System with and without community battery.

\subsubsection{Environmental Impact Analysis}

Figure 3 estimates and compares $\mathrm{CO} 2$ (Carbon Dioxide) equivalent footprint and savings of different system compositions of the real system. The conversion factor is $0.28307 \mathrm{~kg}$ of CO2 saved for each kilowatt-hour $(\mathrm{kWh})$ produced from a carbon free source, based on RenSmart (https://www.rensmart.com/Calculators/KWH-to-CO2 accessed 1 July 2019). Within a 24 hour period, a residence fitted with PV panels has an additional impact of about 400 grams of CO2 equivalent of imported power when it does not have a battery. However it appears there is no difference within the same 24 hour period with regards to $\mathrm{CO} 2$ savings from export; given the state of other variables. These values are influenced by the battery state of charge at time 0 . 


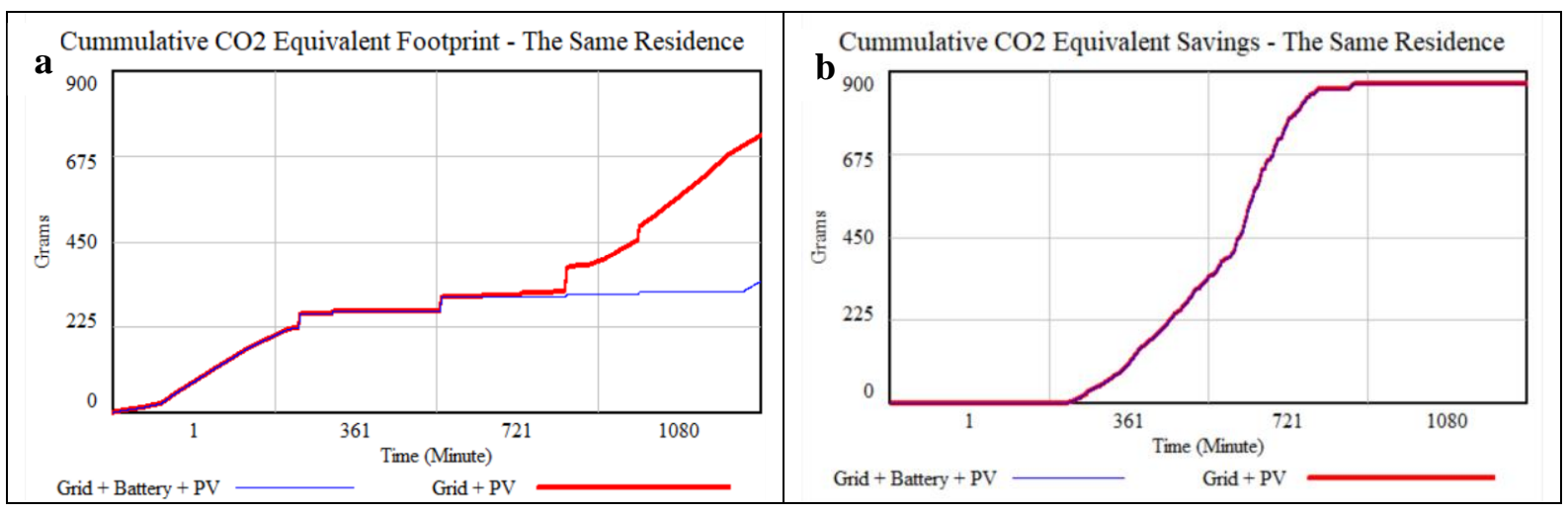

Figure 3 Example of Environmental Impact Analysis: a) Comparing cumulative CO2 equivalent footprint from power import between the same residence with two different compositions; b) Comparing cumulative CO2 equivalent savings power export between the same residence with two different compositions.

\subsubsection{Economic Impact Analysis}

Figure 4 estimates and compares monetary costs and savings of a residence with and without battery, when it is fitted with PV panels. The cost per kWh is based on Green Energy's TIDE tariff for weekdays (https://www.greenenergyuk.com/PressRelease.aspx?PRESS_RELEASE_ID=76 accessed 1 July 2019). Within a 24 hour period, a residence fitted with PV spends in excess of about 25 pence from imported power when it does not have a battery. On the other hand the residence earns about 10 pence in the same period from exporting excess power generated from PV. These values are influenced by the battery state of charge at time 0 . Other system compositions of the real system that can be explored include: Community Energy System with and without battery; centralised community battery and individual residential batteries.
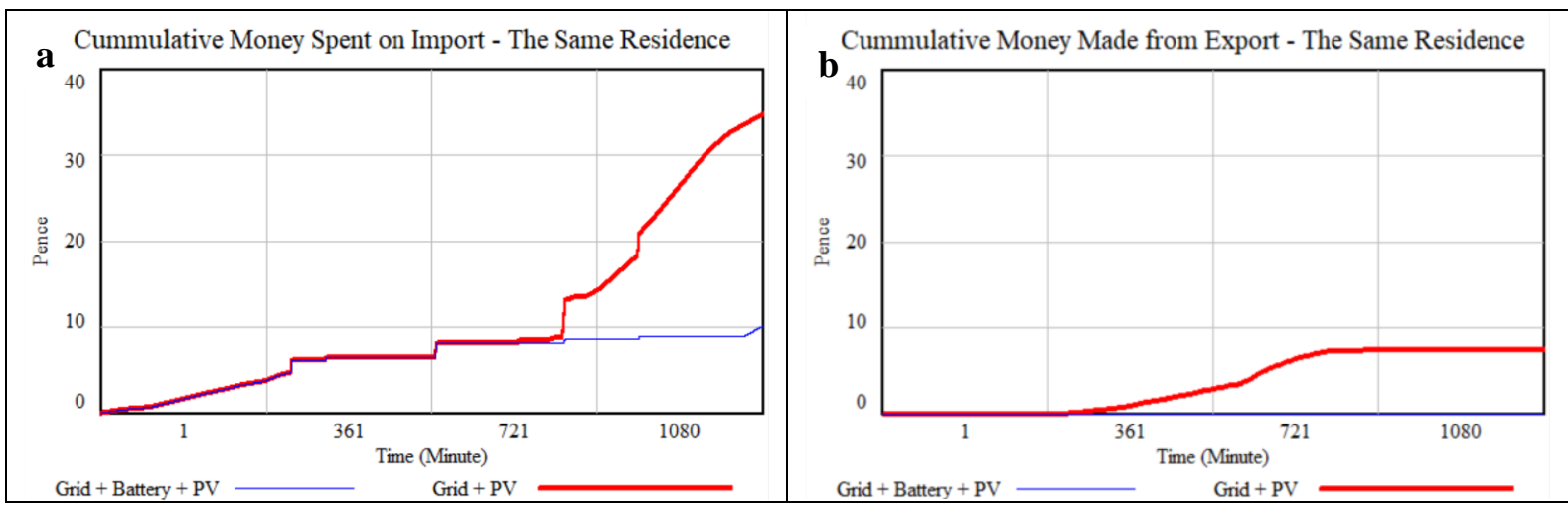

Figure 4 Example of Economic Impact Analysis: a) Comparing cumulative money spent on power import between the same residence with two different compositions; b) Comparing cumulative money earned from power export between the same residence with two different compositions.

\section{CONCLUSION AND FURTHER WORK}

System Dynamics has the capability to model supply-side of residential and community energy systems using a bottom-up approach. The simulation model facilitates systems thinking by being diagrammatic, modular and having multiple layers of detail. In addition, the model features energy conservation, nonlinear conversion efficiency and causal connectedness. Though the model considered the sophisticated optimisation of the real system as exogenous, it behaved like the real system, by mainly relying on the descriptions of use cases. Finally, the model could be used for a number of analyses, and examples have been presented. 
Simulation models like the one presented in this paper could be a step towards allowing the public and prosumers to take part in transdisciplinary Energy Planning, as well as researchers in interdisciplinary and transdisciplinary research. In the future, the model could be expanded to include electric heating and Electric Vehicles (EV). In its current state, the model can be readily integrated with other System Dynamics models that have common variables. An issue worth exploring is the scalability of the community energy systems when it is made up of many residences beyond the few presented in this paper.

\section{ACKNOWLEDGMENTS}

Much thanks to Richard Davies, of FlexElec Laboratory at the University of Nottingham, for clarifying enquiries about the case study and providing data. Also thanks to Petroleum Technology Development Fund (PTDF) for support to one of the authors.

\section{REFERENCES}

Adefarati, T., \& Bansal, R. C. (2019). Reliability, economic and environmental analysis of a microgrid system in the presence of renewable energy resources. Applied Energy, 236(November 2018), 1089-1114. https://doi.org/10.1016/j.apenergy.2018.12.050

Aguilar-Jiménez, J. A., Velázquez, N., Acuña, A., Cota, R., González, E., González, L., ... Islas, S. (2018). Techno-economic analysis of a hybrid PV-CSP system with thermal energy storage applied to isolated microgrids. Solar Energy, 174(August), 55-65. https://doi.org/10.1016/j.solener.2018.08.078

Astriani, Y., Shafiullah, G. M., Anda, M., \& Hilal, H. (2019). Techno-economic evaluation of utilizing a small-scale microgrid. Energy Procedia, 158, 3131-3137. https://doi.org/10.1016/j.egypro.2019.01.1013

Bukar, A. L., Tan, C. W., \& Lau, K. Y. (2019). Optimal sizing of an autonomous photovoltaic/wind/battery/diesel generator microgrid using grasshopper optimization algorithm. Solar Energy, 188(June), 685-696. https://doi.org/10.1016/j.solener.2019.06.050

Castillo-Calzadilla, T., Macarulla, A. M., Kamara-Esteban, O., \& Borges, C. E. (2019). A case study comparison between photovoltaic and fossil generation based on direct current hybrid microgrids to power a service building. Journal of Cleaner Production, 244, 118870. https://doi.org/10.1016/j.jclepro.2019.118870

Checkland, P. (1981). Systems thinking, systems practice John Wiley \& Sons. New York.

Checkland, P. (2012). Four Conditions for Serious Systems Thinking and Action. System Research and Behavioral Science, 29(October), 465-469. https://doi.org/10.1002/sres.2158

Cormio, C., Dicorato, M., Minoia, A., \& Trovato, M. (2003). A regional energy planning methodology including renewable energy sources and environmental constraints. Renewable and Sustainable Energy Reviews, 7(2), 99-130. https://doi.org/10.1016/S1364-0321(03)00004-2

Cornélusse, B., Savelli, I., Paoletti, S., Giannitrapani, A., \& Vicino, A. (2019). A community microgrid architecture with an internal local market. Applied Energy, 242(October 2018), 547560. https://doi.org/10.1016/j.apenergy.2019.03.109

Dhundhara, S., Verma, Y. P., \& Williams, A. (2018). Techno-economic analysis of the lithium-ion and lead-acid battery in microgrid systems. Energy Conversion and Management, 177(September), 122-142. https://doi.org/10.1016/j.enconman.2018.09.030

Forrester, J. W. (1961). Industrial dynamics. Cambridge, Mass.: M.I.T. Press.

Forrester, J. W. (1994). System Dynamics, Systems Thinking, and Soft OR. System Dynamics Review, $10(2), 1-14$.

Forrester, J. W. (Editor). (1997). Road Maps 1-9: A Guide to Learning System Dynamics. System Dynamics in Education Project. System Dynamics Group, Sloan School of Management, Massachusetts Institute of Technology.

Ge, S., Sun, H., Liu, H., Li, J., Zhang, X., \& Cao, Y. (2019). Reliability evaluation of multi-energy microgrids: Energy storage devices effects analysis. Energy Procedia, 158, 4453-4458. https://doi.org/10.1016/j.egypro.2019.01.769 
Griego, D., Schopfer, S., Henze, G., Fleisch, E., \& Tiefenbeck, V. (2019). Aggregation effects for microgrid communities at varying sizes and prosumer-consumer ratios. Energy Procedia, 159, 346-351. https://doi.org/10.1016/j.egypro.2019.01.004

Hall, L. M. H., \& Buckley, A. R. (2016). A review of energy systems models in the UK: Prevalent usage and categorisation. Applied Energy, 169, 607-628. https://doi.org/10.1016/j.apenergy.2016.02.044

He, L., Zhang, S., Chen, Y., Ren, L., \& Li, J. (2018). Techno-economic potential of a renewable energy-based microgrid system for a sustainable large-scale residential community in Beijing, China. Renewable and Sustainable Energy Reviews, 93(October 2016), 631-641. https://doi.org/10.1016/j.rser.2018.05.053

Hong, Y. Y., Chang, W. C., Chang, Y. R., Lee, Y. Der, \& Ouyang, D. C. (2017). Optimal sizing of renewable energy generations in a community microgrid using Markov model. Energy, 135, 6874. https://doi.org/10.1016/j.energy.2017.06.098

Huang, Z., Yu, H., Peng, Z., \& Zhao, M. (2015). Methods and tools for community energy planning: A review. Renewable and Sustainable Energy Reviews, 42(4800), 1335-1348. https://doi.org/10.1016/j.rser.2014.11.042

Kitson, J., Williamson, S. J., Harper, P. W., McMahon, C. A., Rosenberg, G., Tierney, M. J., ... Gautam, B. (2018). Modelling of an expandable, reconfigurable, renewable DC microgrid for off-grid communities. Energy, 160, 142-153. https://doi.org/10.1016/j.energy.2018.06.219

Manfren, M., Caputo, P., \& Costa, G. (2011). Paradigm shift in urban energy systems through distributed generation: Methods and models. Applied Energy, 88(4), 1032-1048. https://doi.org/10.1016/j.apenergy.2010.10.018

Mendes, G., Ioakimidis, C., \& Ferrão, P. (2011). On the planning and analysis of Integrated Community Energy Systems: A review and survey of available tools. Renewable and Sustainable Energy Reviews, 15(9), 4836-4854. https://doi.org/10.1016/j.rser.2011.07.067

Mirakyan, A., \& De Guio, R. (2013). Integrated energy planning in cities and territories: A review of methods and tools. Renewable and Sustainable Energy Reviews, 22, 289-297. https://doi.org/10.1016/j.rser.2013.01.033

Mukherjee, U., Maroufmashat, A., Ranisau, J., Barbouti, M., Trainor, A., Juthani, N., ... Fowler, M. (2017). Techno-economic, environmental, and safety assessment of hydrogen powered community microgrids; case study in Canada. International Journal of Hydrogen Energy, 42(20), 14333-14349. https://doi.org/10.1016/j.ijhydene.2017.03.083

Nnaji, E. C., Adgidzi, D., Dioha, M. O., Ewim, D. R. E., \& Huan, Z. (2019). Modelling and management of smart microgrid for rural electrification in sub-saharan Africa: The case of Nigeria. Electricity Journal, 32(10). https://doi.org/10.1016/j.tej.2019.106672

Project SENSIBLE Partners. (2015). Deliverable 1.1: Energy storage domain roles \& classification. Retrieved from https://www.projectsensible.eu/downloads/

Qudrat-Ullah, H., \& Seong, B. S. (2010). How to do structural validity of a system dynamics type simulation model: The case of an energy policy model. Energy Policy, 38(5), 2216-2224. https://doi.org/10.1016/j.enpol.2009.12.009

Rahmandad, H., \& Sterman, J. (2018). System Dynamics or Agent-Based Models? Wrong question! Seek the right level of aggregation . System Dynamics Society. Retrieved from https://www.systemdynamics.org/assets/docs/sdorabm.pdf

Raji, A. K., \& Luta, D. N. (2019). Modeling and optimization of a community microgrid components. Energy Procedia, 156(September 2018), 406-411. https://doi.org/10.1016/j.egypro.2018.11.103

Randers, J. (1980). Guidelines for model conceptualization. Elements of the System Dynamics Method, 117, 139.

Rathnayaka, A. J. D., Potdar, V. M., Dillon, T., \& Kuruppu, S. (2015). Electrical Power and Energy Systems Framework to manage multiple goals in community-based energy sharing network in smart grid. International Journal of Electrical Power and Energy Systems, 73, 615-624. https://doi.org/10.1016/j.ijepes.2015.05.008

Ravindra, K., \& Iyer, P. P. (2014). Decentralized demand-supply matching using community microgrids and consumer demand response: A scenario analysis. Energy, 76, 32-41. https://doi.org/10.1016/j.energy.2014.02.043 
Richardson, G. P., \& Pugh III, A. I. (1981). Introduction to system dynamics modeling with $D Y N A M O$. Productivity Press Inc.

Richmond, B. (1993). Systems thinking: critical thinking skills for the 1990s and beyond. System Dynamics Review, 9(2), 113-133.

Roberts, N., Andersen, D., Deal, R., Garet, M., \& Shaffer, W. D. (1983). Introduction to Computer Simulation: The System Dynamics Approach.

Sadeghi, H., Rashidinejad, M., \& Abdollahi, A. (2017). A comprehensive sequential review study through the generation expansion planning. Renewable and Sustainable Energy Reviews, 67(May 2016), 1369-1394. https://doi.org/10.1016/j.rser.2016.09.046

Shreckengost, R. C. (1984). DYNAMIC SIMULATION MODELS: HOW VALID ARE THEY?

Sterman, J. (2000). Business dynamics : systems thinking and modeling for a complex world. Boston: Irwin McGraw-Hill.

Takahashi, K, Baker, S, Kurdgelashvili, L. (2005). Policy Options to Support Distributed Resources, $1-94$.

Timmerman, J., Vandevelde, L., \& Van Eetvelde, G. (2014). Towards low carbon business park energy systems: Classification of techno-economic energy models. Energy, 75, 68-80. https://doi.org/10.1016/j.energy.2014.05.092

Van Beeck, N. M. J. P. (1999). Classification of energy models. FEW Research Memorandum, 777, 25.

Xu, D., Mumata, M., \& Mogi, G. (2019). Economic Comparison of Microgrid Systems for Rural Electrification in Myanmar. Energy Procedia, 159, 309-314. https://doi.org/10.1016/j.egypro.2019.01.010

\section{AUTHOR BIOGRAPHIES}

BILAL BUGAJE received a BEng (Hons) Electrical Electronic Engineering from the University of Bradford in 2008. He obtained an MSc Information Technology from the University of York in 2012. $\mathrm{He}$ is currently a PhD student in the Faculty of Engineering at the University of Nottingham since 2018.

PETER RUTHERFORD moved to the University of Nottingham's Department of Architecture and Built Environment in 2002 lecturing in areas including building / architectural science, design studio and environmental psychology. His research at Nottingham has looked at virtual acoustics, the relationship between performers and performance spaces, acoustics within mental health facilities and the impact of acoustics on native and non-native listeners within HE lecture facilities.

https://www.nottingham.ac.uk/engineering/departments/abe/people/peter.rutherford

MIKE CLIFFORD has been at the University of Nottingham since 1994, and is currently an associate professor. His past research include pollution transport studies, car exhaust emissions and building ventilation. Currently, his research areas include appropriate technology, composite materials, dynamical systems, fluid dynamics.

https://www.nottingham.ac.uk/Engineering/Departments/M3/People/mike.clifford 